\title{
PRODUCTION OF LARGE-SCALE MICROCRYSTALLINE FORGINGS FOR ROLL FORMING OF AXIALLY SYMMETRIC ALLOY 718 COMPONENTS
}

\author{
V.A. Valitov, B.P. Bewlay*, O.A. Kaibyshev, Sh.Kh. Mukhtarov \\ C.U. Hardwicke*, M.F.X. Gigliotti* \\ Institute for Metals Superplasticity Problems, 39 Khalturin Street, Ufa 450001, Russia. \\ *General Electric Corporate Research and Development, P.O. Box 8, \\ Schenectady, NY 12301, USA.
}

\begin{abstract}
Large-scale preforms with microcrystalline (MC) structures are required for superplastic (SP) roll forming of turbine components. The MC type microstructures are very important for alloy 718 because its flow stress is higher than that for other nickel base alloys, even under optimum SP conditions. The high flow stress represents a significant challenge for efficient net shape forming of alloy 718 components. This paper will describe the development of regimes for generating MC structures in large-scale preforms of alloy 718. It will be shown that large-scale alloy 718 preforms (up to $150 \mathrm{~kg}$ ) can be produced with a grain size of $2-7 \mu \mathrm{m}$ by isothermal deformation under the correct temperature and strain rate conditions. Complex-shaped rings and disks of alloy 718 have also been manufactured by roll forming under SP conditions. The microstructure and mechanical properties of forgings and roll formed parts after thermomechanical processing will be described.
\end{abstract}

\section{Introduction}

Maximum material utilization is a major consideration in forging aerospace components, due to the high cost of the premium grade rotor materials. Material utilization becomes an increasing concern with large parts that have complex geometries that are difficult to forge. Complex shaped components also typically require expensive dies. The material conversion efficiency can be especially low in processing axially symmetric parts that have conical shapes, flanges, or complex internal geometries. Local shape forming by methods such as shear forming, axial roll forming or rotary drawing can provide very efficient ways of addressing this problem if the forming method is practiced under SP conditions. The process of SP roll forming was developed at the Institute for Metals Superplasticity Problems [1], and it employs pairs of small opposed rollers to shape a cylindrical preform into a complex axisymmetric shape. The rolls are moved radially outward on the preform while it is rotated about its axis of symmetry.

Implementation of novel technologies for producing complex shaped parts by local shape forming under SP conditions can only be achieved using preforms (forgings) with microcrystalline (MC) or submicrocrystalline (SMC) structures; these structures display high ductility and relatively low flow stresses during SP deformation [1-5].

Superalloys 718.625, 706 and Various Derivatives

Edited by E.A. Loria

TMS (The Minerals, Metals \& Materials Society), 2001 
One of the alloys most widely used in turbine engines is alloy 718. A specifically "tailored" sheet version of alloy 718 is INCONEL alloy $718 \mathrm{SPF}$, which was designed for SP forming processes. However, the process regimes used for generating MC structures in sheet can not be used to produce large diameter billets for roll forming. The aim of the present work was to establish the optimum thermo-mechanical regimes for producing large preforms/semi-finished products with MC structures, and to use these preforms to form complex shaped components using SP forming methods.

\section{Materials and Experimental Procedure}

The chemical composition of the alloy 718 that was used in this work is shown in Table 1 . Samples of alloy 718 were machined from 200 and $250 \mathrm{~mm}$ diameter billets. The $200 \mathrm{~mm}$ billets were triple melted (VIM+ESR+VAR), and the $250 \mathrm{~mm}$ billets were double melted (VIM+VAR). Compression tests were conducted over a wide range of temperatures (800$\left.1100^{\circ} \mathrm{C}\right)$ and strain rates $\left(1.5 \times 10^{-4}-1.3 \times 10^{-2} \mathrm{~s}^{-1}\right)$. Cylindrical samples, $10 \mathrm{~mm}$ in diameter and 15 $\mathrm{mm}$ high, were compressed using a SCHENK-PSA testing machine. Deformation of larger diameter billets was performed using samples $40 \mathrm{~mm}$ in diameter and $60 \mathrm{~mm}$ in height, in a 100 ton press under isothermal conditions. Isothermal forging of samples, $40 \times 40 \times 60 \mathrm{~mm}$, was conducted using an isothermal die unit on a 630 ton press with varying deformation directions. Large-scale preforms with MC structures were then generated using a 1600 ton press equipped with isothermal dies. The preforms were then used to superplastically form rings and discs using the SRD-800 rolling mill [1] and a modernized PNC-600 rolling mill.

Table 1. Composition of the alloy 718 that was used for the present study.

\begin{tabular}{|c|c|c|c|c|c|c|c|}
\hline \multicolumn{7}{|c|}{ Concentrations (wt. \%) } \\
\hline $\mathrm{Ni}$ & $\mathrm{Cr}$ & $\mathrm{Fe}$ & $\mathrm{Nb}$ & $\mathrm{Mo}$ & $\mathrm{Ti}$ & $\mathrm{Al}$ & $\mathrm{C}$ \\
\hline balance & $\mathbf{1 9 . 0}$ & $\mathbf{1 8 . 0}$ & $\mathbf{5 . 1}$ & $\mathbf{3 . 1}$ & $\mathbf{1 . 0}$ & $\mathbf{0 . 5}$ & $\mathbf{0 . 0 5}$ \\
\hline
\end{tabular}

\section{Experimental Results}

\section{$\underline{\text { Initial Microstructure }}$}

In the initial condition, the alloy 718 had a completely recrystallized structure with an average grain size of $\sim 40 \mu \mathrm{m}$. The typical alloy 718 billet microstructure is shown in Figure 1 . Investigation of the microstructure of the alloy showed that within the $\gamma$-phase grains there is a uniform distribution of disk-like $\gamma^{\prime \prime}$-phase disk-type precipitates. The diameter of $\gamma^{\prime \prime}$-phase disks was $\sim 60 \mathrm{~nm}$, and they were $\sim 20 \mathrm{~nm}$ thick. The $\gamma^{\prime \prime}$-phase precipitates were also observed on grain boundaries.

\section{Mechanical Properties}

The temperature dependence of the flow stress of the alloy 718 with the initial billet microstructure is shown in Figures 2 and 3 at strain rates of $5.0 \times 10^{-3} \mathrm{~s}^{-1}$ and $5.0 \times 10^{-2} \mathrm{~s}^{-1}$, respectively. At temperatures of 800 to $950^{\circ} \mathrm{C}$ and at all the strain rates investigated, the flow stress increased during the initial stages of plastic deformation and reached a peak at a strain between 10 and $20 \%$. Further deformation led to softening, and at greater strains (more than $30 \%$ ) a steady-state condition was observed on the stress-strain curves. 


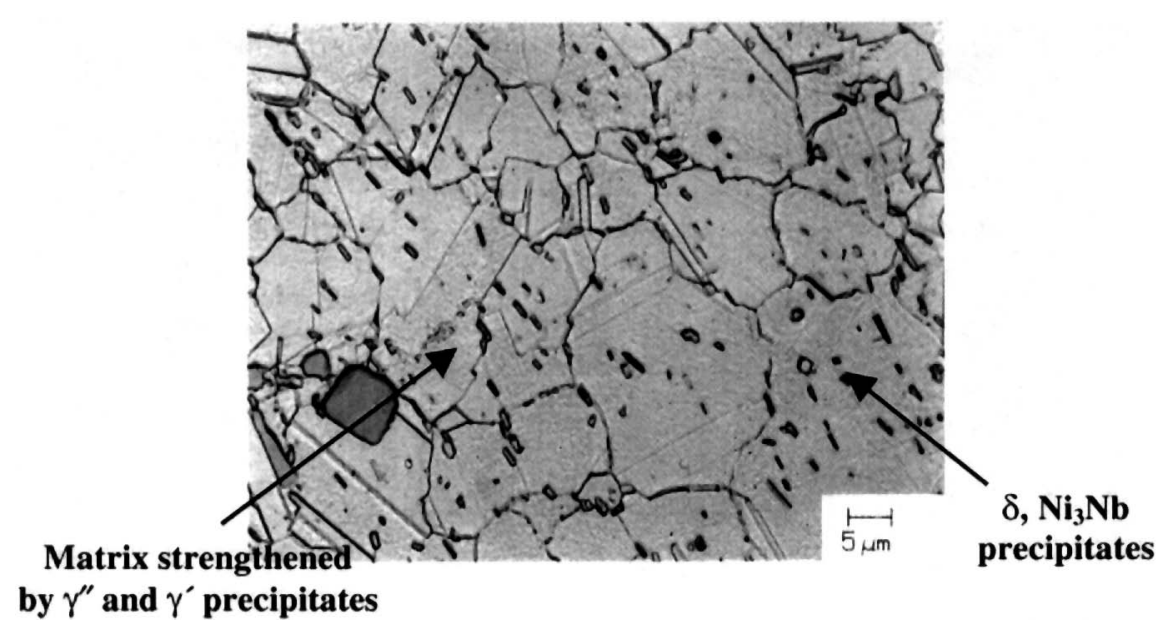

Figurel. Microstructure of typical alloy 718 billet.

At $950^{\circ} \mathrm{C}$ and higher, steady-state plastic deformation was observed on the stress-strain curves. At a constant strain rate of $5.5 \times 10^{-3} \mathrm{~s}^{-1}$, increasing the temperature decreased the flow stress. As the strain rate was reduced from $5 \times 10^{-2} \mathrm{~s}^{-1}$ to $5 \times 10^{-4} \mathrm{~s}^{-1}$, the flow stress also decreased.

\section{Microstructural Changes During Hot Deformation}

Analysis of the microstructures of samples deformed to a strain of $75 \%$ at a strain rate of $5.5 \times 10^{-3} \mathrm{~s}^{-1}$ indicated the following. Dynamic recrystallization occurred throughout the structure after deformation at temperatures from $975^{\circ} \mathrm{C}$ to $1100^{\circ} \mathrm{C}$, based on the flow stress curves and the TEM observations. Over this temperature range, the recrystallized grain size decreased from $40 \mu \mathrm{m}$ (at $1100^{\circ} \mathrm{C}$ ) to $7 \mu \mathrm{m}$ (at $975^{\circ} \mathrm{C}$ ). Further reduction in the deformation temperature to 950 $900^{\circ} \mathrm{C}$ decreased the grain size to $3-4 \mu \mathrm{m}$. The volume fraction of recrystallized grains formed after deformation was also reduced to $33 \%$ (at $950^{\circ} \mathrm{C}$ ) and $20 \%$ (at $900^{\circ} \mathrm{C}$ ). After deformation at $850^{\circ} \mathrm{C}$, recrystallization was observed only near the grain boundaries of the initial grains. The recrystallized grain size was $\sim 1 \mu \mathrm{m}$. At deformation temperatures of $800^{\circ} \mathrm{C}$ and below, a SMC structure with a grain size of $0.1-0.5 \mu \mathrm{m}$ was formed near the original grain boundaries.

The MC structure is not necessarily formed within the whole sample on deformation. Thus, the role of post-deformation annealing, and step-by-step deformation with post-deformation annealing, were investigated. It was determined that after a two-hour post-deformation anneal of samples deformed at $950^{\circ} \mathrm{C}$ and a strain rate of $5.5 \times 10^{-4} \mathrm{~s}^{-1}$, complete recrystallization of the microstructure occurred, generating a grain size of $4.5 \mu \mathrm{m}$, but only in the central region of the compressed sample.

\section{Formation of MC Structures}

High strain thermomechanical processing (TMP) can be used to generate a MC microduplex structure in alloy 718. The high strain TMP generates dynamic recrystallization, modification of the size and morphology of the $\delta$ precipitates, and modification of their coherency with the matrix. Detailed analysis of the microstructural changes during hot deformation [6] allowed us to establish an understanding of the transformation of the coarse-grained billet microstructure to the MC structure. The process by which the MC structure is formed in alloy 718 is described schematically in Figure 4. This model was developed using TEM data from as-deformed alloy 718 samples. 


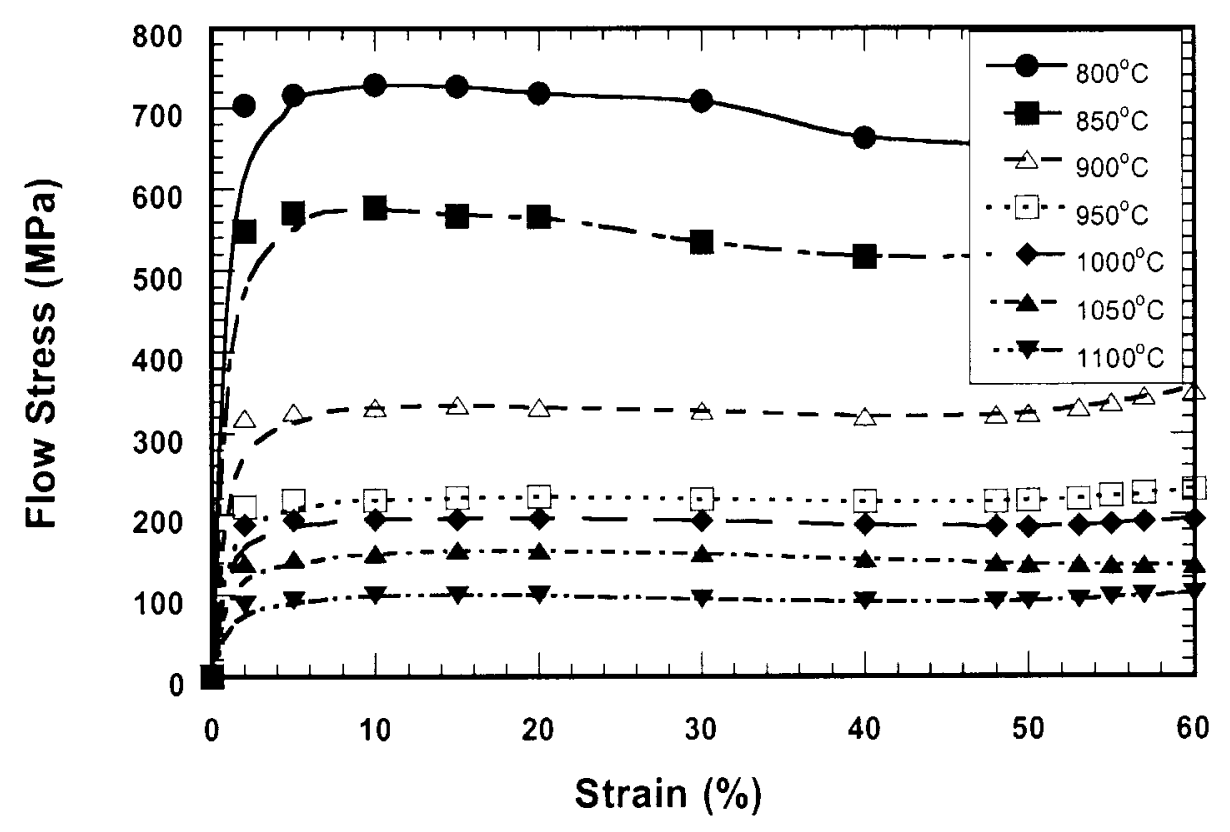

Figure 2. Alloy 718 flow stress as a function of strain for a strain rate of $5 \times 10^{-3} \mathrm{~s}^{-1}$. Tests were performed on the initial alloy 718 billet for strains up to $75 \%$.

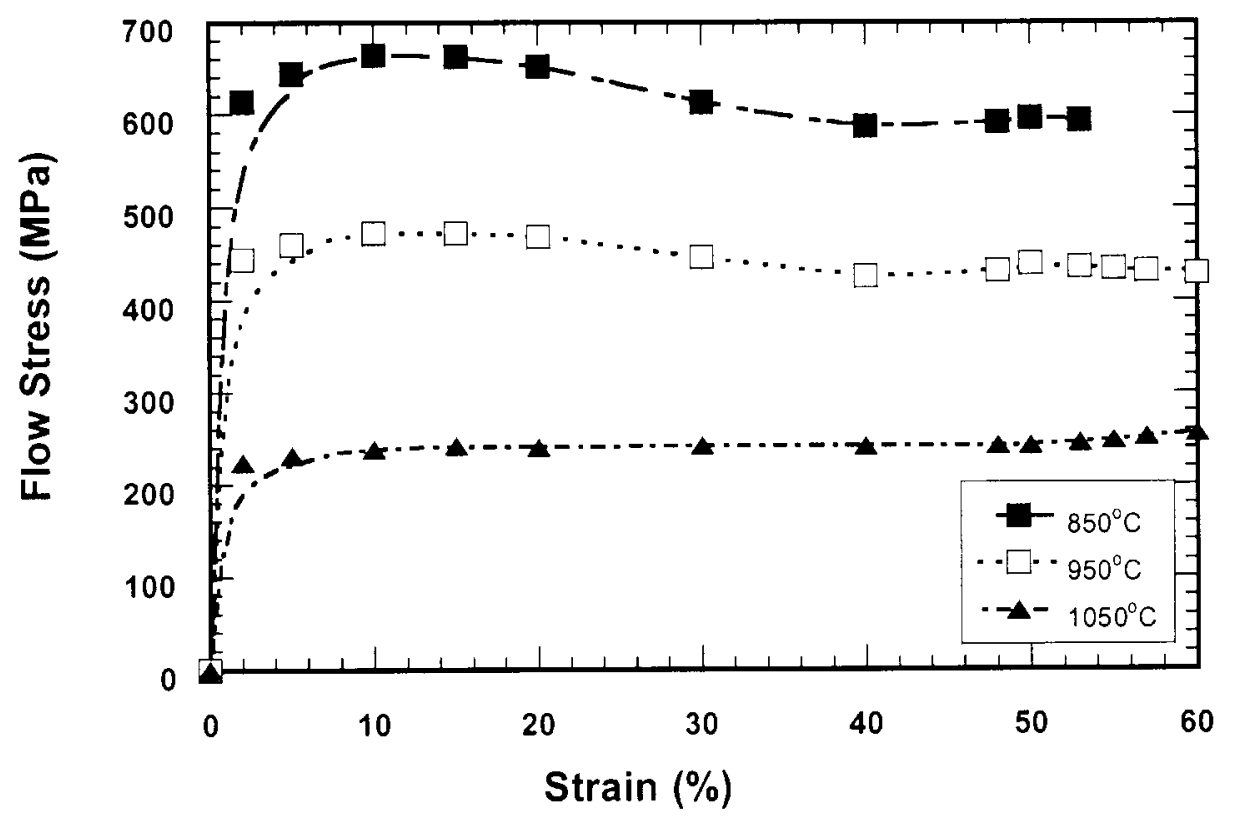

Figure 3. Alloy 718 flow stress as a function of strain for a strain rate of $5 \times 10^{-2} \mathrm{~s}^{-1}$. Tests were performed on the initial alloy 718 billet for strains up to $75 \%$. 


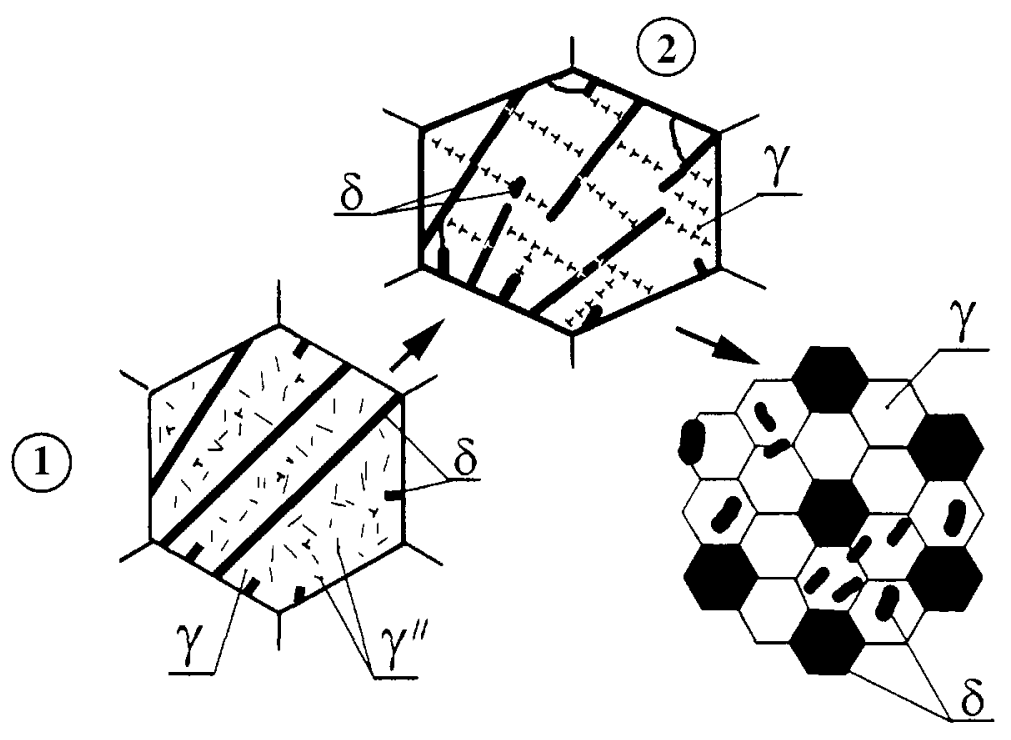

(3)

Figure 4. Model of the transformation of a coarse-grained alloy 718 structure into an $\mathrm{MC}$ structure in the $\gamma+\delta$ regime.

In the initial stage of deformation almost complete dissolution of the $\gamma^{\prime \prime}$-phase occurs. Intragranular dislocation slip increases the dislocation density and leads to the formation of dislocation walls which become piled up against $\delta$-phase plates. The build-up of high local stresses on the $\gamma / \delta$ interfaces leads to the formation of transverse dislocation boundaries inside the particles. As the strain increases, a structure of subgrains forms within the matrix; increasing the strain increases the misorientation between subgrains, eventually leading to the formation of high-angle grain boundaries. High rate diffusional processes and grain boundary sliding at interphase and intergranular boundaries leads to fragmentation of the $\delta$ phase plates and loss of coherency between the $\delta$-phase precipitates and the matrix. Increasing the strain to $50-75 \%$ leads to transformation of the subgrains to new grains with high angle boundaries, and transformation of $\delta$-phase fragments to globular particles with random orientations with respect to the $\gamma$ matrix.

\section{Isothermal Forging}

The distribution of deformation within a preform during compression is not uniform, and therefore in order to generate a recrystallized structure throughout the whole volume of the preform, isothermal forging with a series of different deformation directions was used. Samples with dimensions of $40 \times 40 \times 60 \mathrm{~mm}$ were deformed in the regimes described above according to the following scheme: compression by $50 \%$, drawing by $20-40 \%$, and compression by $50-75 \%$. After this deformation sequence at $950^{\circ} \mathrm{C}$, a MC structure with a grain size of $5 \mu \mathrm{m}$ was formed almost throughout the sample. Similar TMP at $850^{\circ} \mathrm{C}$ generated an $\mathrm{MC}$ structure with a grain size of $1 \mu \mathrm{m}$, and at lower temperatures the TMP sequence generated an SMC structure with a grain size of $0.3-0.5 \mu \mathrm{m}$. In order to generate a recrystallized structure throughout the whole volume, this TMP scheme was performed twice.

\section{$\underline{\text { SP Deformation of Alloy } 718 \text { with MC Structures }}$}

Data showing the dependence of flow stress during isothermal compression of alloy 718 with an $\mathrm{MC}$ structure are shown in Figure 5. The results of these compression tests show that alloy 
718 with $\mathrm{MC}$ structure displays SP behavior. In the temperature range $925-950^{\circ} \mathrm{C}$, the strain rate sensitivity coefficient, $\mathrm{m}$, is $0.5-0.6$ for strain rates of $7 \times 10^{-4}-1 \times 10^{-3} \mathrm{~s}^{-1}$. This value of $\mathrm{m}$ is consistent with tensile data reported previously [7]. At higher strain rates, the value of $\mathrm{m}$ decreases to 0.3 , while the flow stress increases up to $170-210 \mathrm{MPa}$ at a strain rate of $7 \times 10^{-3} \mathrm{~s}^{-1}$. Microstructural analyses of deformed samples indicated that after deformation at a strain rate of $7 \times 10^{-3} \mathrm{~s}^{-1}$ in the temperature range $800-1050^{\circ} \mathrm{C}$ the microstructure remains fine-grained. The average grain size is $4 \mu \mathrm{m}$ at $900^{\circ} \mathrm{C}$ and $8 \mu \mathrm{m}$ at $1050^{\circ} \mathrm{C}$.

\section{Formation of MC Structures in Large-Scale Preforms}

The TMP regimes that were determined for the formation of MC structures in small samples were used for the production of large-scale MC preforms of alloy 718. For fabrication of the ring type forgings, $200 \mathrm{~mm}$ diameter triple-melted alloy 718 billet was used, while for fabrication of the bowl shaped forgings the $250 \mathrm{~mm}$ diameter double-melted billet was used.

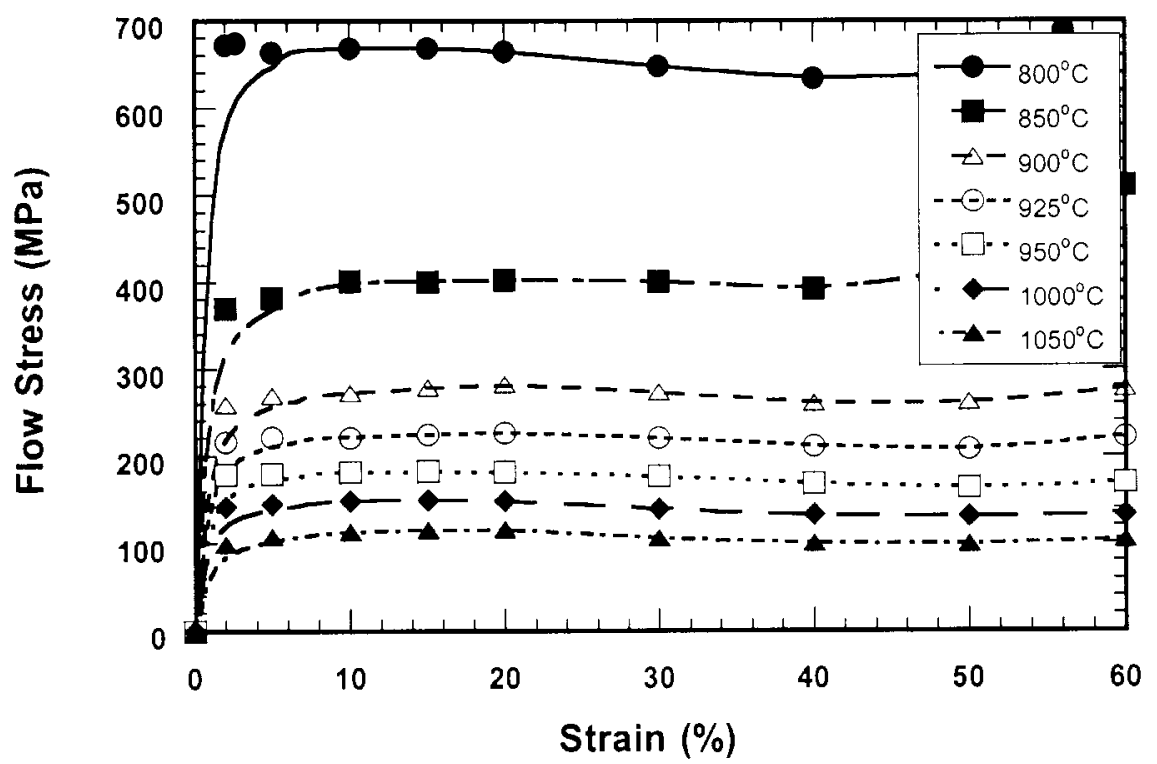

Figure 5. MC alloy 718 (grain size $\sim 3 \mu \mathrm{m}$ ) flow stress as a function of strain (up to $75 \%$ ) for a strain rate of $7 \times 10^{-3} \mathrm{~s}^{-1}$.

Analysis of the initial microstructure of billets showed that the alloy 718 produced by triple melting was uniform. The mean grain size was $\sim 40 \mu \mathrm{m}$. The material produced by double melting possessed traces of dendritic segregation in the ingot that was detected in the billet, even after TMP. As a result, the double melted billet was subjected to a homogenization anneal at $1100^{\circ} \mathrm{C}$ for 20 hours prior to further TMP. After the homogenization anneal the initial grain size increased from 60 to $100 \mu \mathrm{m}$.

The technology for producing preforms with MC structures consisted of several operations. The first stage was production of pancake forgings using isothermal dies at temperatures 975 $900^{\circ} \mathrm{C}$. Typical forgings are shown in the photograph in Figure 6. The second stage consisted of production of ring and bowl type forgings using tooling, such as spacers and complex rings made from the large-grain cast $\mathrm{Ni}$-base superalloy. Isothermal forging was employed for the present study. This provided well controlled deformation and homogenous microstructures. However, it would probably also be possible to employ low strain rate hot die forging methods to develop MC and SMC microstructures. 


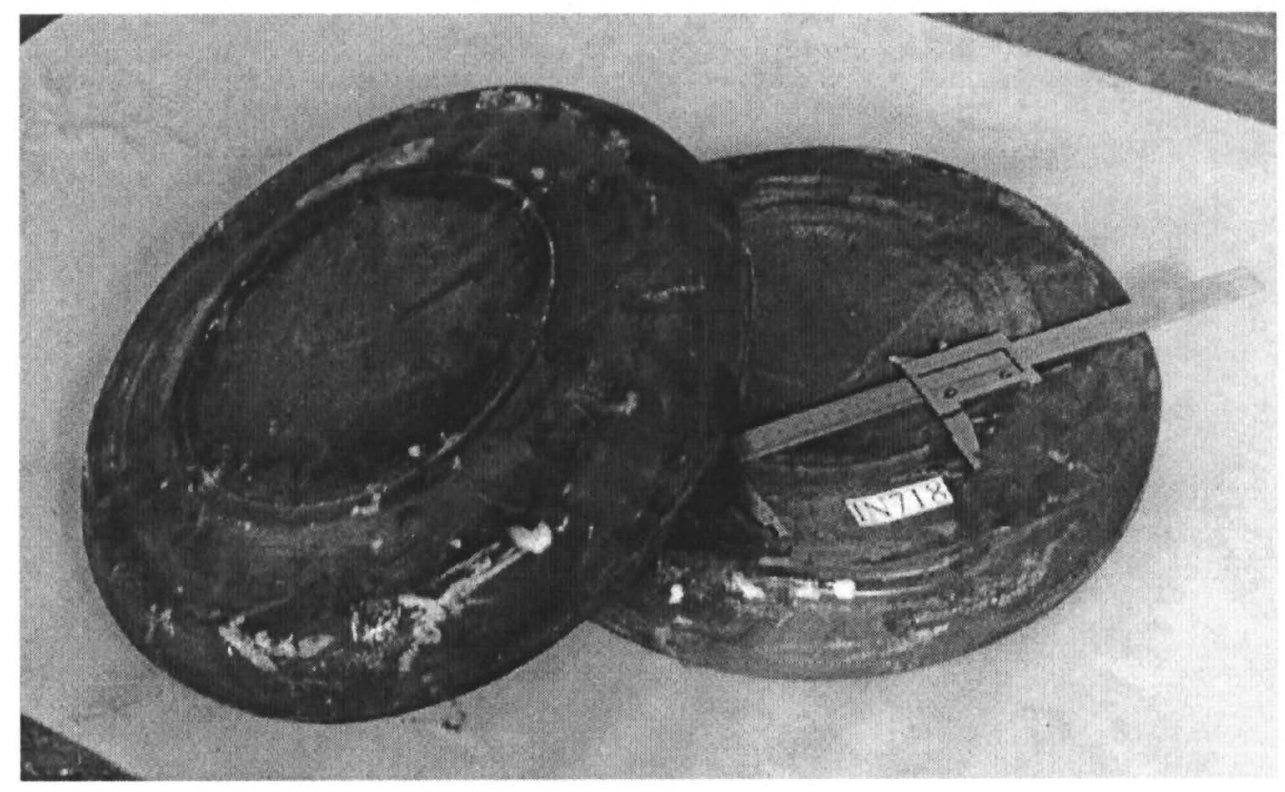

Figure 6 . Photographs of the alloy 718 forgings that were produced by upset forging at temperatures of 900 to $975^{\circ} \mathrm{C}$.

Microstructural analysis of the samples cut from the centers of the forgings showed that a MC structure with an average grain size of $5 \mu \mathrm{m}$ was formed in the ring type forgings, as shown in Figure 7(a). Microstructural analysis of samples from the bowl type forgings showed that a grain size of $3-5 \mu \mathrm{m}$ was formed, and the regions with this grain size constituted $\sim 70 \%$ of the microstructure. In addition to the fine-grained regions, there were regions with a coarser grain size (up to $10 \mu \mathrm{m}$ ); these were probably formed on post-deformation annealing. Regions with only a partially recrystallized structure were also observed. These constituted a volume fraction of less than $30 \%$. The non-uniformity of the structure was probably associated with incomplete homogenization of the double melted billet.

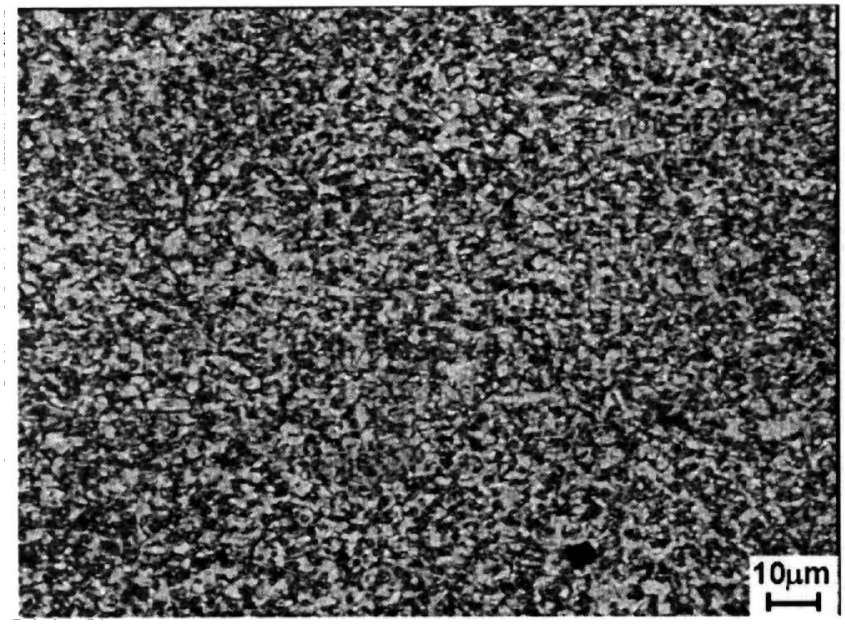

(a)

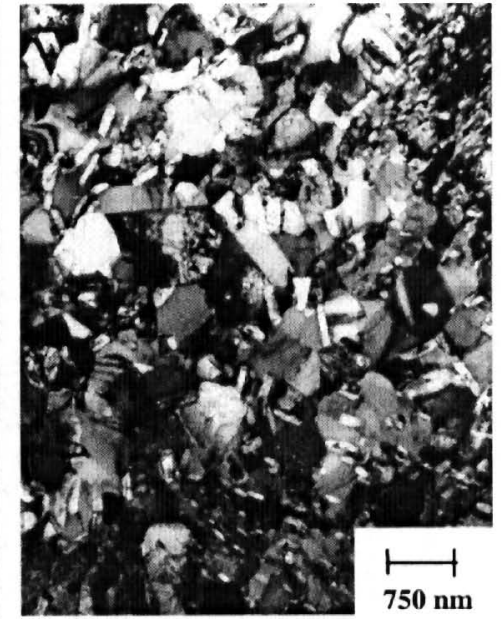

(b)

Figure 7. (a) The microstructure of the alloy 718 at the center of forging. The microstructure is a duplex structure of $\gamma$ and $\delta$ phases. (b) Microstructure of the alloy 718 after forging at a strain rate of $5.5 \times 10^{-3} \mathrm{~S}^{-1}$ and $850^{\circ} \mathrm{C}$ to generate an MC structure. 
Roll forming of rings was performed on the SRD-800 rolling mill using the techniques reported previously [8]. The scheme for roll forming rings is shown in Figure 8. The SRD-800 mill was designed for roll forming titanium billets and, as a result, its load limit is relatively low. The temperature that was selected for roll forming of alloy 718 was $1050-1075^{\circ} \mathrm{C}$, and it was higher than the optimum temperature for superplasticity because of the limited load capability of the mill. Analysis of the microstructure of the central region of the ring revealed a coarse-grained microstructure with a grain size of $\sim 75 \mu \mathrm{m}$, while at the periphery of the ring, which is the region in direct contact with rollers, the grain size was smaller $(\sim 50 \mu \mathrm{m})$. The homogenous triple melted alloy 718 was roll formed above the $\delta$ solvus, and this led to a larger grain size.
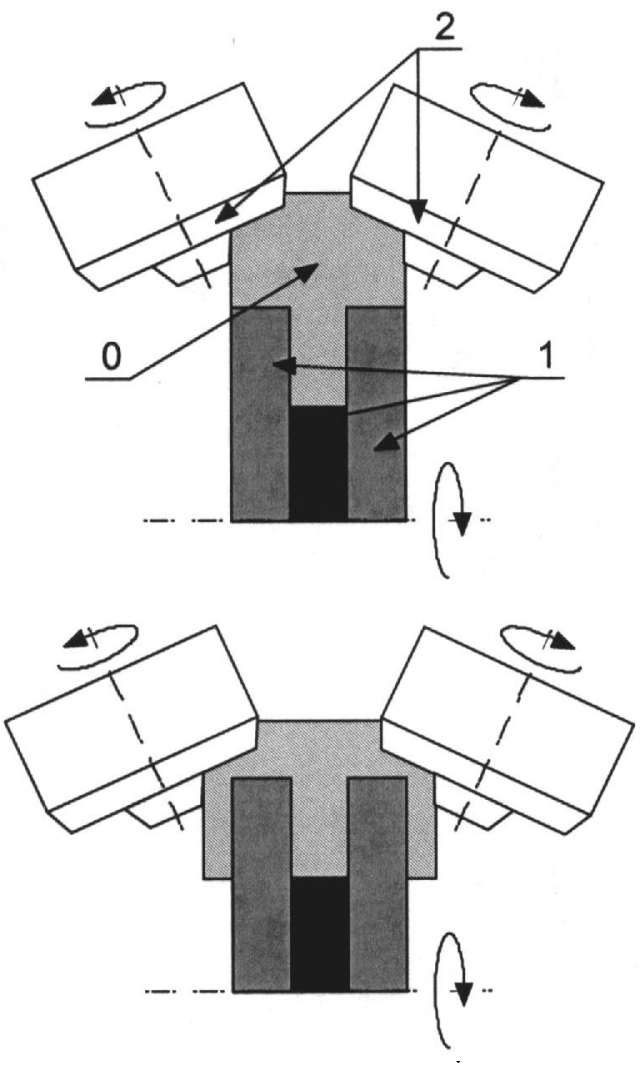

Figure 8. Schematic diagram of roll forming of disks. Item 0 is the preform, and item 2 is the rollers. Items 1 are the forming mandrels.

Roll forming of a disc with a conical flange (Figure 9) was conducted in the SP temperature regime $\left(950^{\circ} \mathrm{C}\right)$ using two passes. The bowl shaped isothermal forging was used. The first pass consisted of rotary drawing of a cylindrical portion on the disk. The second pass consisted of shape forming of the conical shaped flange on the disk. The scheme for roll forming the flange is shown in Figure 10. The double melted alloy 718 was roll formed below the $\delta$ solvus and thus the microstructure was finer than that observed in the roll formed ring. However, there is some inhomogeneity in the microstructure that is probably associated with chemical segregation in the double melted billet. Microstructural analysis of the roll formed disc showed the following. The initial partially recrystallized structure of the forging was preserved in the hub zone of the disc (the region that is perpendicular to the axis of symmetry of the disk), which was not subject to rotary drawing. In the more heavily deformed zone (the conical region of the disk) a more uniform fine-grain structure with a grain size of 5-7 $\mu \mathrm{m}$ was formed. 


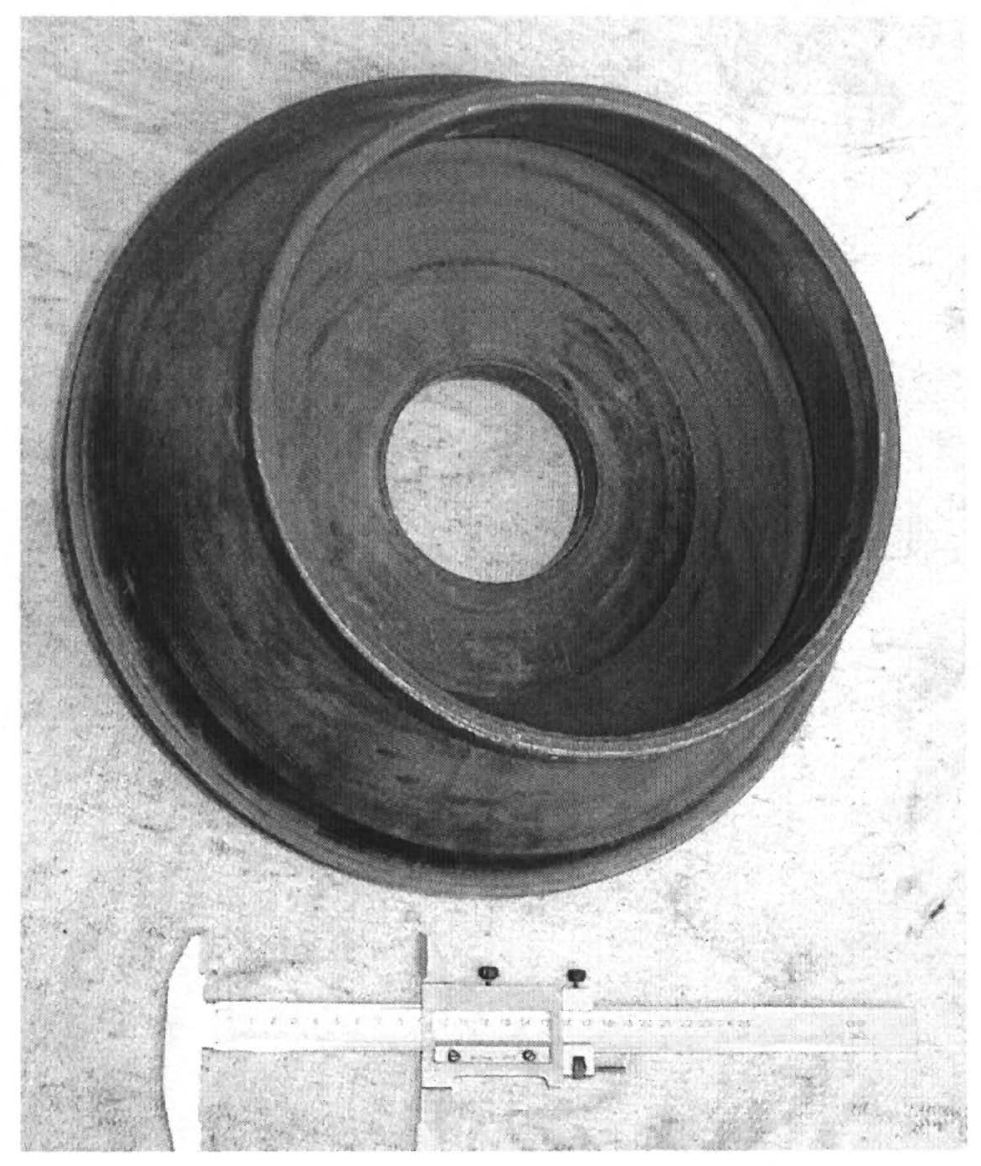

Figure 9. Photograph of the conical alloy 718 disk after roll forming. The internal contour of the disk is visible.

This occurred because during roll forming intense dynamic recrystallization occurred, and it provided a refined microstructure in those regions not processed by the prior isothermal forging. In the conical region of the disk the microstructure was uniform and fine-grained, as shown in Figure 11. In the hub region, where the microstructure was only partially recrystallized prior to roll forming, the macrostructure was less uniform and individual coarse grains were observed.

\section{Discussion}

Analysis of the above results has shown that high strain hot deformation and subsequent annealing at the deformation temperature can generate a completely recrystallized microduplex type structure in large alloy 718 forgings with masses up to $150 \mathrm{~kg}$. During post-deformation annealing between TMP passes, the recrystallization processes, which started as dynamic recrystallization during forging, can continue. The anneal increases the degree of recrystallization to a level of $70 \%$ and higher. Reduction of the TMP temperature decreases the recrystallized grain size. In particular, decreasing the deformation temperature to $850^{\circ} \mathrm{C}$ generates an $\mathrm{MC}$ structure with a grain size of $1 \mu \mathrm{m}$, and a further reduction generates a SMC structure with a grain size of $<1 \mu \mathrm{m}$. However, for a completely recrystallized SMC structure throughout the whole volume of the forging, the structure should be subjected to intense multiaxial TMP, such as isothermal forging, or other methods of plastic deformation [9]. 


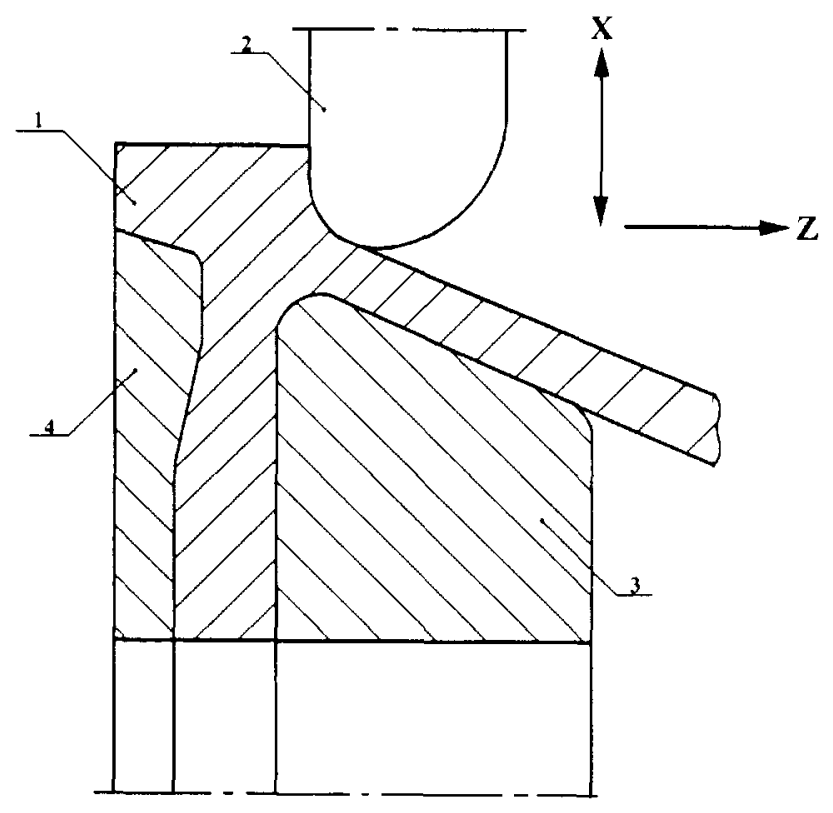

Figure 10. Schematic diagram of roll-forming of the flange on the alloy 718 disk. Item 1 is the preform, and item 2 is the external roller. Items 3 and 4 are forming mandrels.

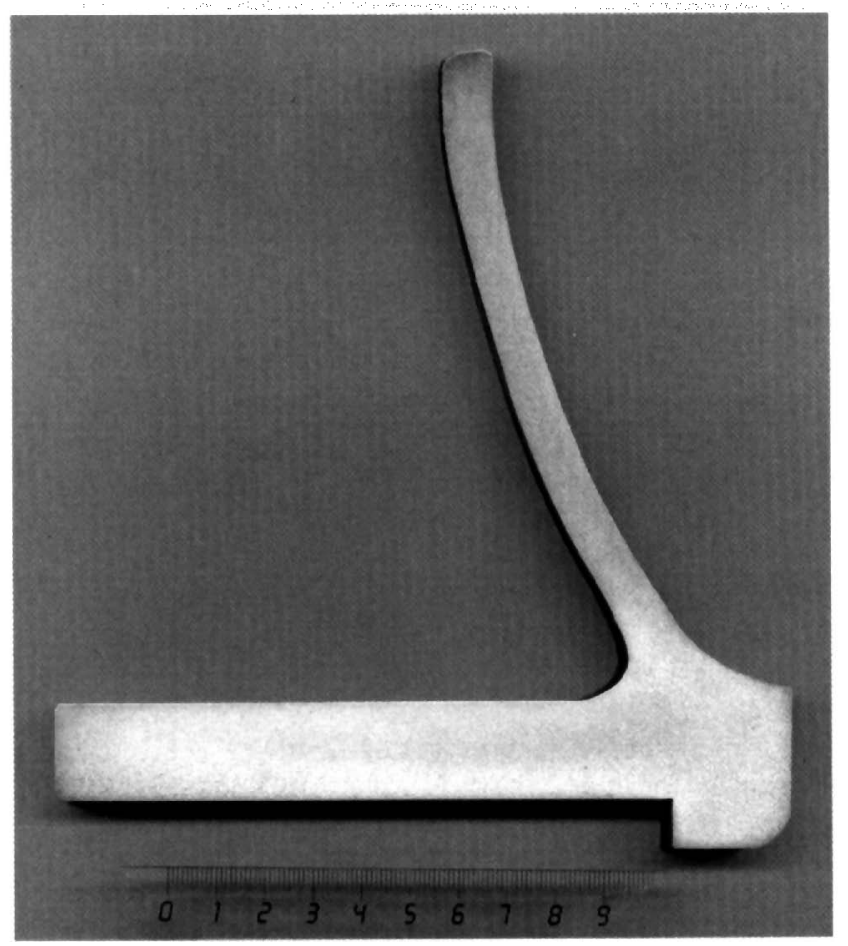

Figure 11. Macrostructure of the longitudinal section of the alloy 718 disk after roll forming. The macrograph shows essentially no flow lines.

An unusual feature of SP deformation of the alloy 718 is that even with an MC structure it displays a high flow stress (about $100 \mathrm{MPa}$ ), even at very low strain rates. In a number of cases this can be a major barrier for SP forging of alloy 718 . However, SP deformation of forgings with MC structures in conjunction with local forming technologies allows production of complex-shaped parts with profiles that cannot be forged, for example, disc type parts with conical flanges. So, the use of SP deformation in conjunction with local forming technologies, 
such as roll forming or rotary drawing, can significantly increase the efficiency of production of large-scale complex shaped parts of high-strength nickel base alloys.

\section{Conclusions}

The results obtained in the present study provide the following conclusions:

1. High strain-thermomechanical processing can be used to produce large-scale preforms and forgings with $\mathrm{MC}$ and SMC microstructures.

2. Isothermal forging can be employed in conjunction with the high strain-thermomechanical processing. Gradual and sequential reductions in the deformation temperature allow production of large-scale alloy 718 billets with uniform $\mathrm{MC}$ and SMC microstructures. The uniform microstructures are achieved using multi-axial deformation in conjunction with post-deformation anneals.

3. Local forming (roll forming or rotary drawing) under SP conditions provides an efficient method for producing large-scale alloy 718 parts with complex profiles that can not be forged. These technologies can also be applied to other nickel base alloys, including $\gamma^{\prime}$ strengthened alloys.

\section{Acknowledgements}

The authors would like to thank T.B. Cox, P.S. Follansbee, and J.C. Shei for arranging the inter-laboratory collaboration between GE-CRD and IMSP. The authors would also like to acknowledge partial financial support from the US Air Force under contract F33615-99-2-5216.

\section{References}

[1] B.P. Bewlay, M.F.X. Gigliotti, F.Z. Utyashev and O.A Kaibyshev, Materials and Design, Vol. 21 (2000), 287-295.

[2] O.A. Kaibyshev, F.Z. Utyashev, and V.A. Valitov, Metal. Term. Obr. Met., Vol. N7 (1989), 40-44.

[3] O.A. Kaibyshev, Superplasticity of Alloys, Intermetallides and Ceramics, Springer Verlag, Berlin (1992), 316.

[4] G.A. Salishchev, O.R. Valiakhmetov, V.A. Valitov, and Sh.Kh. Mukhtarov, Mater. Sci. Forum, ICSAM 94, Vol. 170-172, (1994), 121.

[5] V.A Valitov, G.A. Salishchev, and Sh.Kh. Mukhtarov, Mater. Sci. Forum, ICSAM97, Vol. 243-245 (1997), 557.

[6] V.A. Valitov, F.Z. Utyashev, and Sh. Kh. Mukhtarov, Mater. Sci. Forum, Vol. 304-306 (1999), 79-84.

[7] V.A. Valitov, B.P. Bewlay, Sh.Kh. Mukhtarov, O.A Kaibyshev, and M.F.X. Gigliotti, Mat. Res. Soc. Symp. Proc., Vol. 601 (2000), 43-48.

[8] F.Z. Utyashev, R.G. Baimurzin, and V.A. Plekhov, Kuznechno-Shtampovochnoe Proizvodstvo, Vol. 7 (1999), 14-16.

[9] R.Z. Valiev, I.V. Alexandrov, Nanostructural Materials Produced by Severe Plastic Deformation, Logos, Moscow (2000), 272. 